\title{
Effects of Nonsteroidal Anti-inflammatory Drugs on the Self-renewal Capacity of Blast Progenitors in Hematological Malignancies
}

\author{
ZHANG YI $^{1}$, ZHAO YAN ${ }^{1}$, KAZUMA MIYAHARA ${ }^{2}$, MAI SHIMADA ${ }^{2}$, KEN-ICHI TANAKA $^{3}$, \\ HIROYUKI HAYASHI ${ }^{4}$, NORIKO IHARA ${ }^{2}$ and IKUO MUROHASHI ${ }^{1}$ \\ ${ }^{1}$ Hematology, Center for University-Wide Education, ${ }^{2}$ Department of Health Sciences, \\ ${ }^{3}$ Physiology, Center for University-Wide Education, and ${ }^{4}$ Anatomy, Center for University-Wide Education, \\ School of Health and Social Services, Saitama Prefectural University, Saitama, Japan
}

\begin{abstract}
Background: With our newly established longterm suspension culture, we investigated the effects of nonsteroidal anti-inflammatory drugs (NSAIDs) on the selfrenewal capacity of blast progenitors in seven hematological malignant cell lines. Materials and Methods: Cyclo-oxygenase inhibitors NS-398 (NS) or indomethacin heptyl ester (indomethacin) at $30 \mu M$ was added to the cell culture. In U-937 cells, indomethacin was added at 0.3 or $3 \mu M$. Results: In all cell lines, the agents significantly and markedly inhibited blast colony formation (BCF) and telomerase activity, respectively. Significant exponential clonogenic cell growth was noted under all 23 conditions with or without the agent. The relative slope (SLP) of the line $\left(S L P_{\text {agent }} / S L P_{\text {control }}\right)$ reflects the level of self-renewal induced by the agent and self-renewal was inhibited (relative SLP at 0.9 or below) in four out of 16 conditions, including in U-937 cells treated with 0.3 or $3 \mu M$ indomethacin, in Daudi cells treated with indomethacin and in U-266 cells treated with NS. Indomethacin enhanced senescence, necrosis and apoptosis in U-937 and Daudi cells, whereas NS reduced apoptosis in U-937 cells and had no effect on senescence, necrosis and apoptosis in Daudi cells. In U-266 cells, NS enhanced senescence and necrosis, whereas indomethacin reduced apoptosis. There
\end{abstract}

This article is freely accessible online.

Correspondence to: Dr. Ikuo Murohashi, Hematology, Center for University-Wide Education, School of Health and Social Services, Saitama Prefectural University, Sannomiya 820, Koshigaya-City, Saitama 343-8540, Japan. Tel/Fax: +81 489734796, e-mail: murohashi-ikuo@spu.ac.jp

Key Words: NSAIDs, hematological malignancies, long-term suspension culture, self-renewal capacity, blast colony formation, terminal divisions, telomerase. was no significant correlation between the control of $B C F$ and relative SLP. Conclusion: NSAIDs enhance or reduce stress responses, inhibit telomerase activity and differentially regulate $B C F$ and self-renewal.

In acute myeloid leukemia and acute lymphoblastic leukemia, leukemia stem cells arise either from hematopoietic stem cells or more differentiated and committed progenitors that acquire self-renewal (SR) potential $(1,2)$. Secondary blast colony formation (BCF) in methylcellulose and recovery of clonogenic cells in suspension, but not primary BCF, were significantly associated with remission induction (3). Furthermore, the survival duration of patients who achieved complete remission was significantly associated with the number of clonogenic cells recovered in suspension.

The preventive role of nonsteroidal anti-inflammatory drugs (NSAIDs) and aspirin, in particular, in colorectal cancer is well established (4). More recently, NSAIDs have been shown to reduce the risk and mortality from several cancer types (5). However, the molecular mechanisms involved in NSAIDs-mediated tumor-suppressing activities are not yet completely defined $(6,7)$.

In the present study, we investigated the growth of hematological malignant blast progenitors in liquid suspension for up to 1 month by serial re-plating following continuous exposure to cyclo-oxygenase (COX)-2-specific inhibitor NS-398 (NS) and COX1 and -2 inhibitor indomethacin heptyl ester (indomethacin). Primary BCF in methylcellulose was carried out to assess the terminal divisions of blast progenitors (3). Regulatory mechanisms including telomerase activity, stress responses such as senescence, necrosis and apoptosis, and their rates were also serially determined. As far as we are aware of, this is the first report describing the inhibition by NSAIDs of SR capacity in hematological malignant blast progenitors. 


\section{Materials and Methods}

Cell lines. HL-60 (kindly provided by Dr D.W. Golde, UCLA School of Medicine, LA, CA) is a myeloid cell line derived from a patient with acute promyelocytic leukemia. Mo7e (a kind gift of Dr S. Tohda, Tokyo Medical and Dental University, Tokyo, Japan) is a subclone of the human megakaryoblastic-leukemia cell line Mo7. The cells require either interleukin-3 (IL-3) or granulocytemacrophage colony-stimulating factor for long-term growth. K-562 is a myeloid cell line derived from a patient with chronic myelogenous leukemia in myeloid crisis. Daudi and Raji are Blymphoid cell lines derived from patients with Burkitt's lymphoma. U937 is a human histiocytic, monocyte-like cell line derived from a patient with diffuse histiocytic lymphoma. K562, Daudi, Raji and U937 were purchased from the Japanese Collection of Research Bioresources Cell Bank (Osaka, Japan). Human myeloma cell line, U-266, was kindly provided by $\mathrm{Dr}$ M. Kawano (Yamaguchi University School of Medicine, Ube, Japan).

Materials. Iscove's modified Dulbecco's medium (IMDM) (Gibco), fetal calf serum (FCS), and phosphate-buffered saline (PBS) were from Gibco (Grand Island, NY, USA). Trypan blue (TB) was from Sigma (Tokyo, Japan). Indomethacin heptyl ester (indomethacin) [halfmaximal inhibitory concentration $\left(\mathrm{IC}_{50}\right)$ for human $\left.\mathrm{COX} 2=0.04 \mu \mathrm{M}\right]$ and NS (Cayman Chemical Company, Ann Arbor, MI, USA) as a COX2-specific inhibitor $\left(\mathrm{IC}_{50}=1.77 \mu \mathrm{M}\right)$ were from Cayman Chemical Company. Recombinant human (rh) IL3 was a generous gift from Dr. S. Clark (Genetics Institute, Cambridge, MA, USA).

Clonogenic cell assay in methylcellulose culture. BCF was performed as previously reported (8).

Long-term suspension culture. Cells were cultured at a density of 104/ml in 35-mm Lux tissue culture dishes (Miles Lab., Naperville, IL, USA) in $2 \mathrm{ml}$ of IMDM with $10 \%$ FCS in the presence or absence of hematopoietic growth factor (HGF) (10 ng/ml rh IL3 for Mo7e) and agents (30 $\mu \mathrm{M}$ NS or indomethacin). In U-937 cells, indomethacin was added at 0.3 or $3 \mu \mathrm{M}$. Control contained $0.38 \%$ dimethyl sulfoxide (DMSO) alone. Twice a week, the cells were harvested, counted, washed and plated in 96-microwell plates at a density of $2 \times 10^{3}$ per well in $0.1 \mathrm{ml}$ of IMDM with $1 \%$ methylcellulose, $10 \%$ FCS, in the presence or absence of HGF ( $10 \mathrm{ng} / \mathrm{ml} \mathrm{rh}$ IL3 for Mo7e) to obtain the plating efficiency. The recovery of clonogenic cells per dish was obtained by multiplying this plating efficiency by the number of cells harvested from the suspension. At each subculture, the harvested cells were transferred into fresh medium in the presence or absence of agent, and the cumulative number of clonogenic cells (CCCs) per dish with time was calculated.

Calculation of kinetic parameters for cumulative clonogenic cells. The numbers of CCCs from start of liquid suspension culture were serially plotted on semilogarithmic graphs. Linear regression analysis using SPSS Statistics was performed. The line of the fitted equation describing the plots and the significance of linearity were determined (9). The relative slope (SLP) (rSLP) of the line defined as the ratio of $\mathrm{SLP}_{\text {agent }} / \mathrm{SLP}_{\text {control }}$ indicated the level of SR under treatment by the agent.

TB staining. A mixture of equal volumes of $0.4 \% \mathrm{~TB}$ solution in $0.85 \%$ saline and cell suspension was kept for $5 \mathrm{~min}$ at room temperature, and cells stained blue were counted as positive. For quantification of TB-positively stained cells, 100 cells were counted in three separate fields using an inverted Nikon microscope (Nikon, Tokyo, Japan) and the proportion of TB-positive cells was determined. Since loss of membrane integrity is a pathognomonic feature of necrotic cell death, necrotic cells stain with specific membrane-impermeable nucleic acid dyes such as TB in contrast to viable cells (10).

SA- $\beta$-galactosidase labeling. SA- $\beta$-galactosidase was detected by using Senescence Detection Kit (BioVision Inc., Milpitas, CA, USA). Briefly, cells were fixed for 15 min with Fixative Solution, then washed once with PBS. Cells were then incubated overnight at $37^{\circ} \mathrm{C}$ with Staining Solution Mix containing $1 \mathrm{mg} / \mathrm{ml} \mathrm{X-Gal.} \mathrm{For}$ quantification of SA- $\beta$-galactosidase-positively stained cells, 100 cells were counted in three separate fields using an inverted Nikon microscope and the proportion of SA- $\beta$-galactosidase-positive cells was determined.

Apoptotic cell fraction. Propidium iodide (PI) staining of DNA in permeabilized cells by cell phase determination kit (Cayman Chemical Company) and its detection by flow cytometry (BD FACSCanto $^{\text {TM }}$ II; BD Biosciences, Tokyo, Japan) were used to identify the hypodiploid cells as the apoptotic cell fraction (11). Fluorescence of PI-stained cells were measured within $30 \mathrm{~min}$ on a FACSCanto $^{\mathrm{TM}}$ II equipped with a doublet discrimination module for $10^{4}$ nuclei.

Telomerase activity. Telomerase activity was assessed using a Quantitative Telomerase Detection Kit (Allied Biotech, Inc., Benicia, CA, USA) according to the manufacturer's protocol. Cells were lysed and protein was isolated using the kit. The concentration of the isolated protein was determined using a NanoDrop Spectrophotometer (Thermo Scientific, Waltham, MA, USA). The telomerase activity in each cell extract was measured from its ability to synthesize telomeric repeats onto an oligonucleotide substrate. The extended product was amplified and visualized using SYBR Green. The increase in fluorescence was monitored, and the telomerase activity was determined using real-time polymerase chain reaction (Chromo 4TM Real-Time PCR System; Bio-Rad, Tokyo, Japan).

Statistics. Data for BCF are shown as the mean \pm SD of five replicate cultures. The other assay determinations were carried out in triplicate. The statistical significance was evaluated using Student's $t$-test (two-tailed).

\section{Results}

Growth regulation in methylcellulose. In all seven cell lines, both agents inhibited $\mathrm{BCF}$ in a dose-dependent manner (Figure 1). The $\mathrm{IC}_{50}$ for NS and indomethacin ranged from 9.2 to $>30$ and 3.6 to $>30 \mu \mathrm{M}$ with a mean of $>27.0$ and $>26.2 \mu \mathrm{M}$, respectively. Thus, in the subsequent experiments, we cultured cells in suspension with NS and indomethacin at a final concentration of $30 \mu \mathrm{M}$, which inhibited BCF by $43 \pm 19 \%$ and $36 \pm 27 \%$ (mean \pm SD of percentage inhibition of control in seven cell lines), respectively. The inhibitory effect on BCF was greater for NS than indomethacin, although 

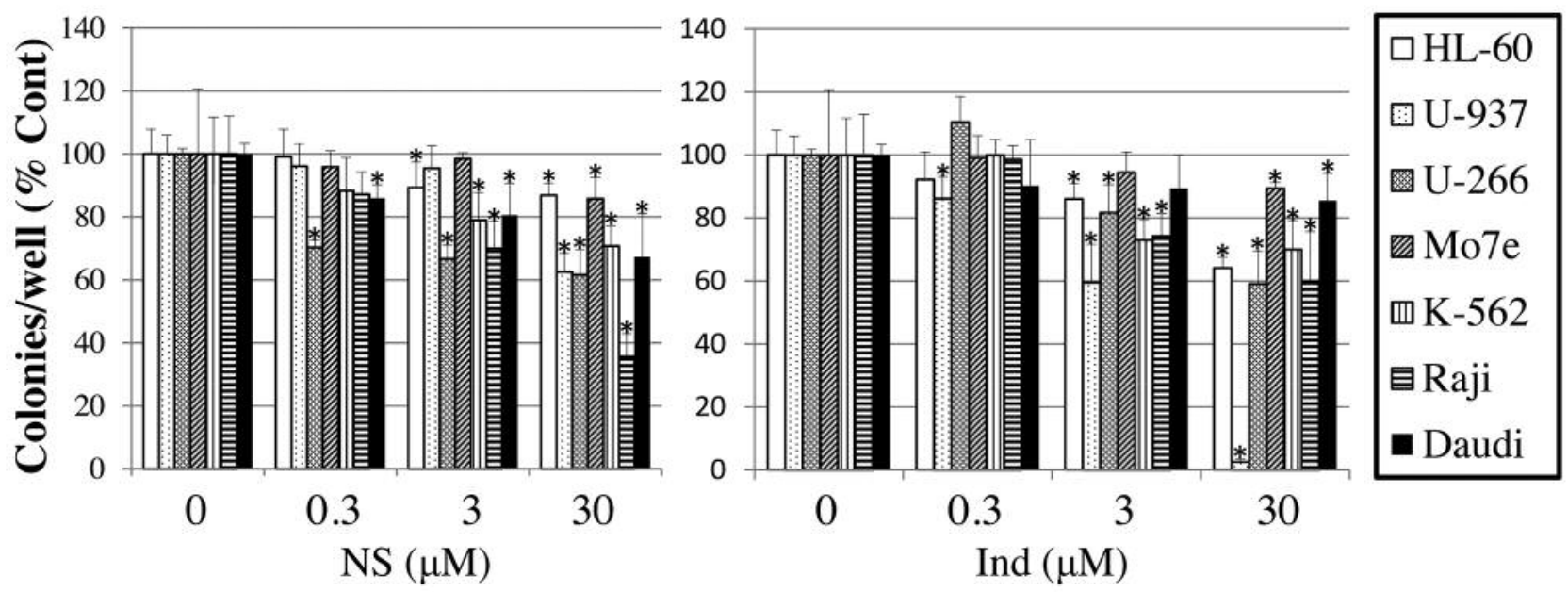

Figure 1. Effects of nonsteroidal anti-inflammatory drugs on blast colony formation BCF in methylcellulose. Full titration curves of NS-398 (NS) and indomethacin (Ind) for the seven cell lines were generated. BCF per well in control culture was 129 $\pm 10,100 \pm 5,115 \pm 2,68 \pm 14,125 \pm 8,70 \pm 9$ and 192 \pm 20 in HL-60, U-937, U-266, Mo7e, K-562, Raji and Daudi cells, respectively. The data shown represent the mean \pm SD of five replicate cultures. The data were normalized as the percentage of the control value in each experiment. Control medium contained $0.38 \%$ dimethyl sulfoxide alone. ${ }^{*} p<0.05$ when compared to control cultures.

there was no significant difference between the two agents. Thus, the final concentrations of agents used were less than the $\mathrm{IC}_{50}$ s except in two cases (Raji with NS and U-937 with indomethacin).

Growth regulation in liquid suspension. A significant logarithmic linear increase in the number of CCCs recovered per dish for up to 1 month was observed under all conditions (seven cell lines treated with or without either agent and U937 treated with indomethacin at 0.3 and $3 \mu \mathrm{M})(p<0.01, r$ ranged from 0.994 to 0.999 with a mean \pm SD of $0.997 \pm 0.002)$ (Figure 2).

Inhibition of SR capacity (rSLP at 0.9 or below) by both agents was observed in four $(25 \%)$ out of 16 conditions, including U-937 with 0.3 or $3 \mu \mathrm{M}$ indomethacin, U-266 with NS and Daudi with indomethacin. In addition, a significant reduction in the number of CCCs by both agents, at least once, was observed under all 16 conditions except for HL60 with both agents. Surprisingly, in U-937 cells, indomethacin at $30 \mu \mathrm{M}$ almost completely abolished BCF (3\% that of the control), but did not affect the SR capacity (rSLP of 1.004), although at 0.3 and $3 \mu \mathrm{M}$ it inhibited SR capacity with rSLP of 0.808 and 0.873 , respectively.

There was no significant correlation $(p>0.05)$ between control of BCF and rSLP in the cell lines using NS $(\mathrm{t}=0.318, r=0.141)$ or indomethacin $(\mathrm{t}=0.647, r=0.278)$ (Figures 1 and 2).

Stress responses of cells in liquid suspension. The rates of each of the three types of stress response, i.e. senescence, necrosis and apoptosis, of the cells in liquid suspension were serially determined (Figures 3 and 4).

In U-937 cells, indomethacin enhanced both senescence and necrosis at days 14 and 17 (Figure 3) and the relative apoptotic ratio by FCM analysis at day 10 (Figure 4). In contrast, NS reduced apoptosis at days 7 and 10, although it enhanced necrosis at day 14 . Thus, BCF was more sensitive to inhibition by indomethacin than by NS. Indomethacin and NS reduced the CCC at re-plating except for day 21 and days 7, 14, 17 and 21, respectively.

In U-266 cells, NS enhanced senescence and necrosis, whereas indomethacin reduced apoptosis, and BCF and SR capacity were more sensitive to the inhibition by NS than by indomethacin.

In Raji cells, NS slightly enhanced and indomethacin slightly reduced apoptosis at days 4 and 7 and day 4 , respectively; BCF was more sensitive to inhibition by NS than by indomethacin. NS and indomethacin ceased to reduce CCC number and both NS and indomethacin and indomethacin alone reduced apoptosis and necrosis at day 10 and 14 , respectively.

In Mo7e cells, cellular stress response by either agents was absent until day 14, and BCF was most resistant to the agents. Indomethacin reduced CCC number at day 14 and enhanced necrosis at day 17.

In K-562 cells, NS and indomethacin scarcely reduced the CCC number until day 4 and 10 and reduced necrosis at day 7 and 14, respectively. Subsequently, NS and indomethacin reduced CCC number at day 10 and 14, respectively, and enhanced necrosis at day 17. 

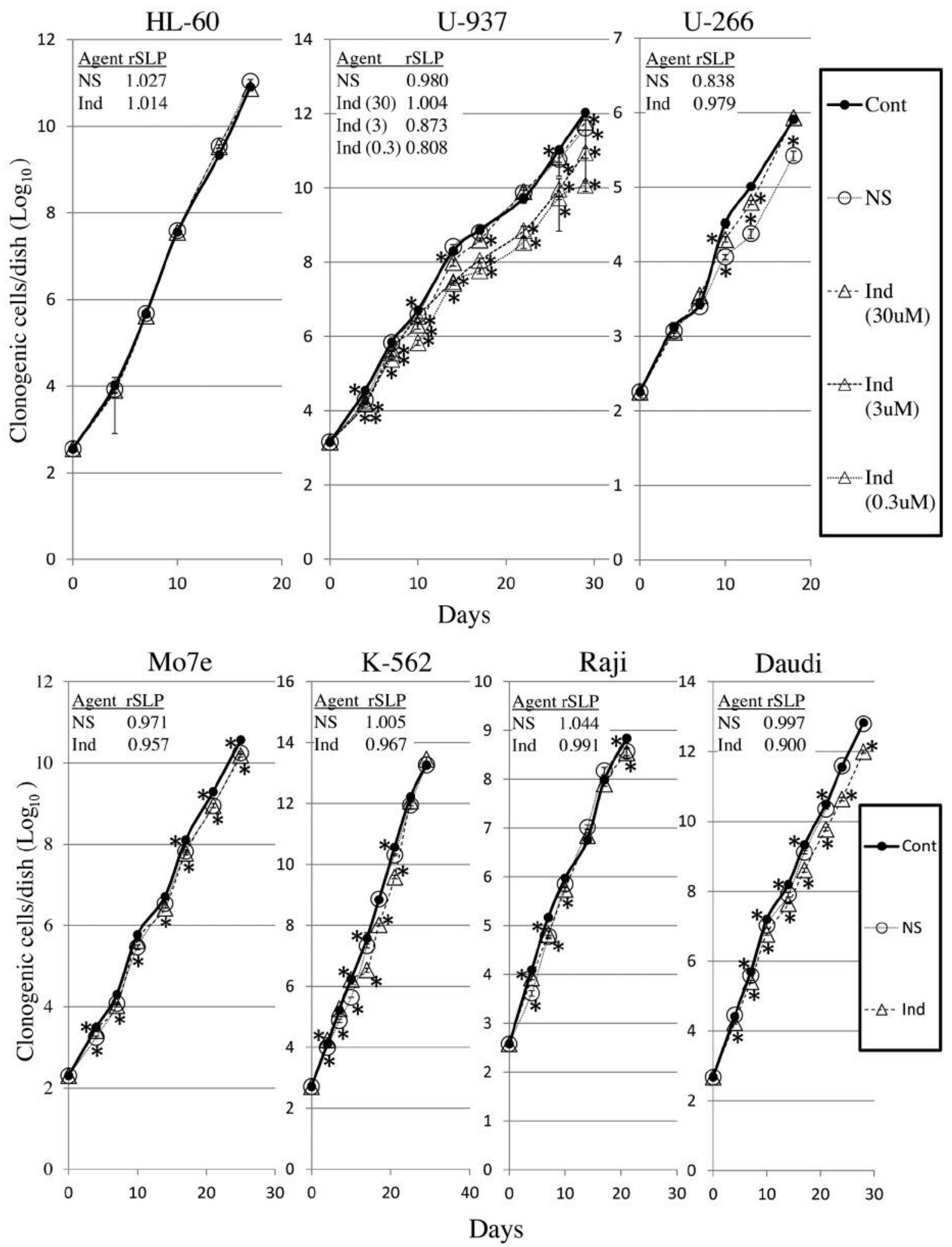

Figure 2. Effects of nonsteroidal anti-inflammatory drugs on cumulative clonogenic cell recovery in long-term suspension cultures of HL-60, $U$ 937, U-266, Mo7e, K-562, Raji and Daudi cells. Cells were cultured in suspension with 0.38\% dimethyl sulfoxide alone (Cont) or with dimethyl sulfoxide plus NS-398 (NS) or indomethacin (Ind). The data shown represent the mean $\pm S D$ of five replicate cultures. Relative slope (rSLP) was expressed as inhibition relative to the control (1.0). ${ }^{*} p<0.05$ when compared to Cont. 

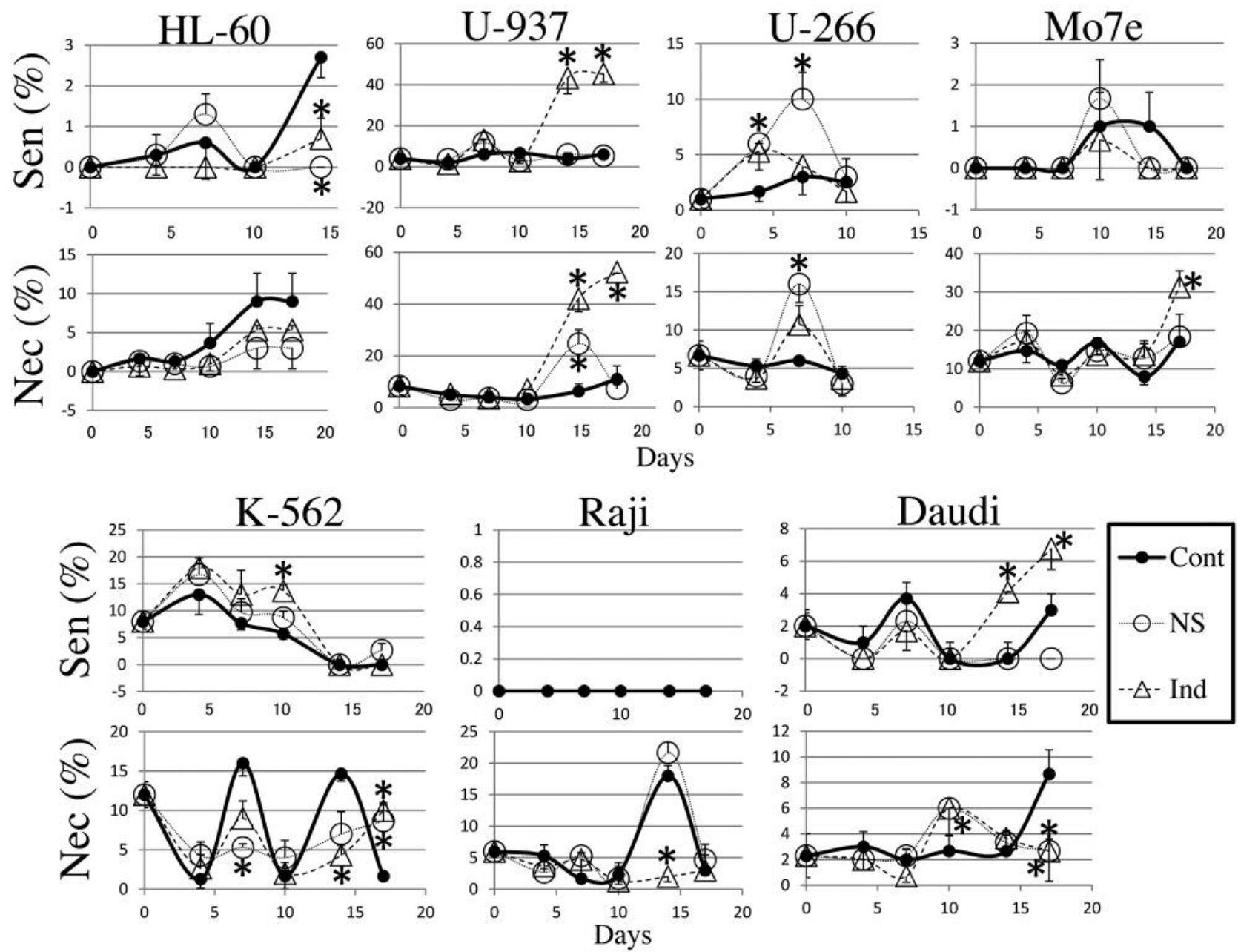

Figure 3. Senescence and necrosis in liquid suspension cultures of HL-60, U-937, U-266, Mo7e, K-562, Raji and Daudi cells. Cells were treated with $0.38 \%$ dimethyl sulfoxide alone (Cont) or with dimethyl sulfoxide plus NS-398 (NS) or indomethacin (Ind). The percentage of cells stained with SA- $\beta$-galactosidase (senescent, Sen) or trypan blue (necrotic, Nec) was determined. The data shown represent the mean \pm SD of three separate measurements. ${ }^{*} p<0.05$ when compared to Cont.

In Daudi cells, indomethacin enhanced apoptosis at days 4 and 7 , necrosis at day 10 , and senescence at day 17 , whereas NS enhanced none of the stress responses. Consequently, SR capacity was more sensitive to inhibition by indomethacin than by NS, although BCF reversely responded to these agents.

Telomerase activity. Both agents markedly reduced telomerase activity at day 4 or 7 in all of the seven cell lines, although the reductions in Daudi cells were not significant (Figure 5).

\section{Discussion}

In the present study, both of the agents significantly inhibited BCF and CCC number in $14(100 \%)$ and 14 (88\%) out of 14 and 16 conditions, respectively. However, there was no significant correlation between the sensitivity to the either agents of the SR capacity in suspension and that of the BCF in methylcellulose. This may be partly owing to the differences in the duration of total exposure to the agent and the subsequently accumulated cellular damage. This is somewhat reflected in the fact that it took more than 6 years to benefit from at least 0.5 to 1.5 standard aspirin tablet use per week in gastrointestinal cancer (12).

According to our criteria, the effect on the three stress responses in seven cell lines was as follows: unchanged: 1/14, 7\%, Mo7e with NS; reduced but not enhanced: $6 / 14$, 43\%, HL-60 and Raji with either agents, U-266 with indomethacin, and Daudi with NS; reduced and enhanced: 4/14, 29\%, K-562 with either agents, U-937 with NS, and Daudi with indomethacin; and enhanced but not reduced: 

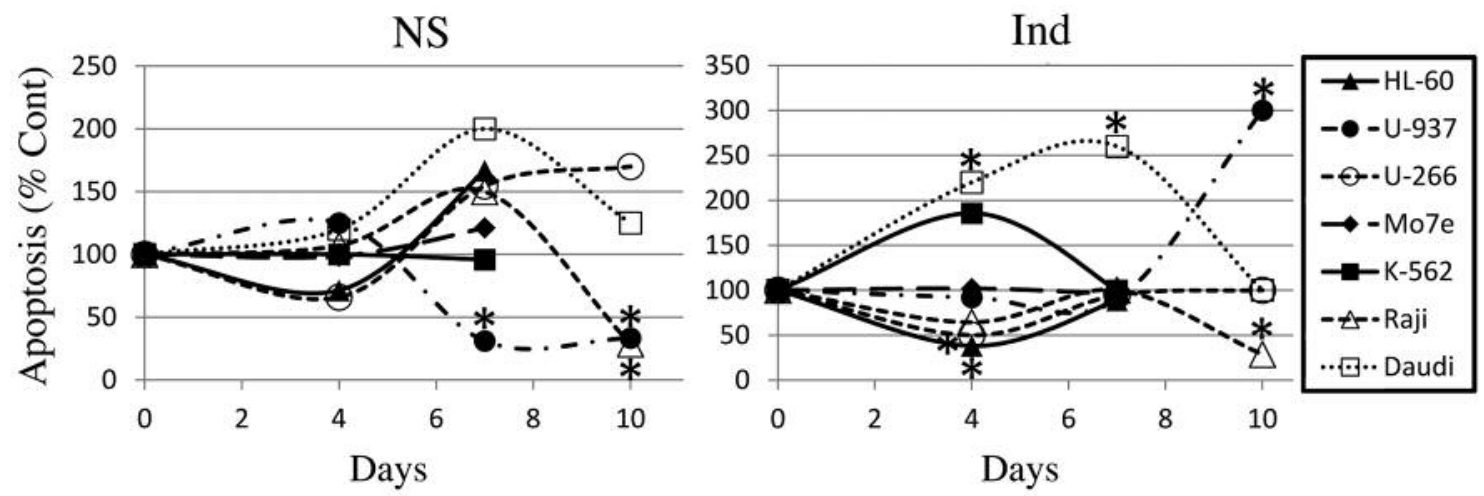

Figure 4. The relative apoptotic cell fraction determined with flow cytometric analysis. HL-60, U-937, U-266, Mo7e, K-562, Raji and Daudi cells were treated with $0.38 \%$ dimethyl sulfoxide alone (Cont) or with dimethyl sulfoxide plus NS-398 (NS) or indomethacin (Ind). The apoptotic cell fraction was determined as described in the Materials and Methods Section. The data were normalized as the percentage of the control value in each experiment. The percentage of apoptotic cells in control cultures was $0.3 \% \pm 0.7 \%(n=7), 4.8 \% \pm 5.6 \%(n=7), 3.1 \% \pm 2.6 \%(n=7)$ and $1.1 \% \pm 0.6 \%$ $(n=4)$ at day 0, 4, 7 and 10, respectively. *Enhancement and reduction of apoptosis was defined as $\geq 200 \%$ and $<50 \%$, respectively.

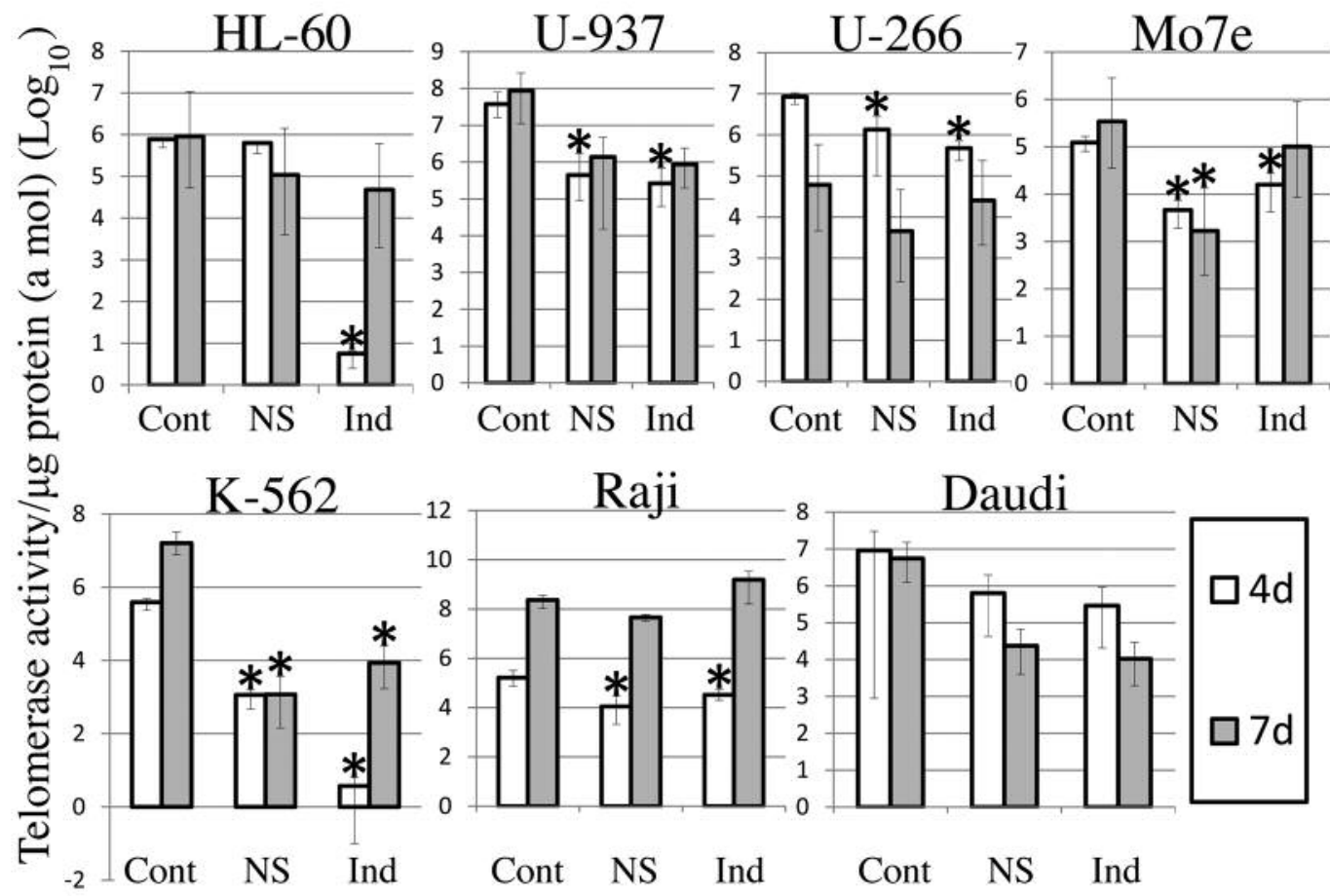

Figure 5. Effects of nonsteroidal anti-inflammatory drugs on telomerase activity in HL-60, U-937, U-266, Mo7e, K-562, Raji and Daudi cells. Cells were treated with $0.38 \%$ dimethyl sulfoxide alone (Cont) or with dimethyl sulfoxide plus NS-398-398 (NS) or indomethacin (Ind). The data shown represent the mean $\pm S D$ of three separate measurements. ${ }^{*} p<0.05$ when compared to Cont.

3/14, 21\%, U-937 and Mo7e with indomethacin and U-266 with NS. Thus, reduced and enhanced stress response was found in $10(71 \%)$ and $7(50 \%)$ out of 14 conditions, respectively. Under six conditions with reduced but without enhanced stress response, rSLP was 0.979 (U-266 with indomethacin) or greater, with a mean of 1.009 . Under 10 conditions with reduced stress response, except for Daudi with indomethacin, rSLP was 0.967 (K-562 with indomethacin) or greater, with a mean of 1.0. In Daudi with indomethacin, enhancement far exceeded reduction. Under 
four conditions without reduced stress response, except for U-937 with indomethacin, rSLP was 0.971 (Mo7e with NS) or less, with a mean of 0.922 . Thus, lack of reduced stress response seems to be necessary to inhibit SR capacity.

Senescence is regarded as a physiological response of cells to stress, including telomere dysfunction, aberrant oncogenic activation, DNA damage and oxidative stress (13). Senescence is characterized by irreversible cell-cycle arrest, overexpression of cyclin-dependent kinase inhibitors, caspase-independent cell death and a strong resistance to apoptosis (14).

In contrast, apoptosis is classified as programmed cell death I, characterized by morphological features such as rounding of the cell and caspase activation (15). Necrosis is usually considered to be uncontrolled and accidental. However, recent research suggests that its occurrence and course might be tightly regulated (16). Recent literature highlights the intricate interplay between apoptosis, necrosis and autophagy in normal development and in pathology (17). It is also reported that the senescence response was potentiated by apoptosis inhibition in an autophagydependent way (18).

NSAIDs have been shown to down-regulate telomerase activity and cancer cell growth in vitro (19). Telomerase inhibition either genetically or pharmacologically limits leukemia stem cell SR capacity through cell-cycle arrest, p53 activation, DNA damage, and apoptosis (20). A noncanonical feed-forward regulatory loop mechanism involved in the cross-talk with telomerase reverse transcriptase between the nuclear factor-kappa $\mathrm{B}$ and $\mathrm{WNT} / \beta$-catenin pathways has been reported (21). Although, in the present study, both agents markedly reduced telomerase activity in all seven cell lines, inhibition of SR was observed in only 4 (25\%) out of 16 conditions. Telomerase inhibition results in stimulation of COX2 and mammalia target of rapamycin complex 1 and inhibition of autophagy $(22,23)$. This may indicate that reduced telomerase activity may be necessary but not sufficient to inhibit SR capacity.

In U-937 cells, $0.3 \mu \mathrm{M}$ indomethacin significantly inhibited BCF and reduced rSLP to 0.808 . In a human clinical trial, $1 \mathrm{~h}$ after a single capsule dosage of $25 \mathrm{mg}$ indomethacin, its concentration in blood of $0.3 \mu \mathrm{M}$ or more was obtained (24). Thus, it may be possible for indomethacin to inhibit malignant hematological SR capacity in vivo.

Aspirin has been shown to inhibit colony formation, SR capacity by spheroid-formation assay and tumor growth in a nude mouse xenograft model in breast and pancreatic cancer $(25,26)$. Our present long-term suspension culture, however, enables us to express the SR capacity of blast progenitors as rSLP, compare each rSLP for different agents alone and in combination, and uncover the growth-regulatory mechanisms by adding stimulators or inhibitors to the culture. Mechanisms of an imbalance between pro-oxidant and antioxidant factors controlled by multiple components in NSAIDs, including positive correlation between indomethacin dose and rSLP in U-937 cells, remain to be further clarified (27).

\section{Acknowledgements}

The Authors are indebted to Drs. Susumu Ohshima and Masami Bessho (Saitama Medical University, Saitama) for analysis and discussion of flow cytometry data and Dr. Ryo Kubota (Saitama Prefectural University) for statistical analysis. This work was supported by a 2013 Graduate Student Exchange and Grant-in-Aid for Encouragement of Scientists Research Funds, Saitama Prefectural University.

\section{References}

1 Goardon N, Marchi E, Atzberger A, Quek L, Schuh A, Soneji S, Woll P, Mead A, Alford KA, Rout R, Chaudhury S, Gilkes A, Knapper S, Beldjord K, Begum S, Rose S, Geddes N, Griffiths M, Standen G, Sternberg A, Cavenagh J, Hunter H, Bowen D, Killick S, Robinson L, Price A, Macintyre E, Virgo P, Burnett A, Craddock C, Enver T, Jacobsen SE, Porcher C and Vyas P: Coexistence of LMPP-like and GMP-like leukemia stem cells in acute myeloid leukemia. Cancer Cell 19: 138-152, 2011.

2 Castor1 A, Nilsson L, Åstrand-Grundström I, Buitenhuis M, Ramirez C, Anderson K, Strömbeck B, Garwicz S, Békássy AN, Schmiegelow K, Lausen B, Hokland P, Lehmann S, Juliusson G, Johansson B and Jacobsen SE: Distinct patterns of hematopoietic stem cell involvement in acute lymphoblastic leukemia. Nat Med 11: 630-637, 2005.

3 Nara N, Kurokawa H, Tanikawa S, Tomiyama J and Nagata K: Prognostic significance of the blast self-renewal capacity in patients with acute myeloid leukemia. Cancer 73: 92-97, 1994.

4 Rothwell PM, Wilspn M, Elwin CE, Norrving B, Algra A, Warlow $\mathrm{P}$ and Meade TW: Long-term effect of aspirin on colorectal cancer incidence and mortality: 20-year follow-up of five randomized trials. Lancet 376: 1741-1750, 2010.

5 Liggett JL, Zhang X, Eling TE and Baek SJ: Anti-tumor activity of non-steroidal anti-inflammatory drugs: cyclooxygenaseindependent targets. Cancer Letters 346: 217-224, 2014.

6 Din FV, Valanciute A, Houde VP, Zibrova D, Green KA, Sakamoto K, Alessi DR and Dunlop MG: Aspirin inhibits mTOR signaling, activates AMP-activated protein kinase, and induces autophagy in colorectal cancer cells. Gastroenterology 142: 1504-1515, 2012.

7 Gurpinar E, Grizzle WE and Piazza GA: NSAIDs inhibit tumorigenesis, but how? Clin Cancer Res 20: 1104-1113, 2014.

8 Murohashi I, Yoshida K, Kishimoto K, Takahashi T, Wakao D, Jinnai I, Yagasaki F, Kawai N, Suzuki T, Matsuda A, Hirashima $\mathrm{K}$ and Bessho M: Differential response to stem cell factor and Flt3 ligand by the FAB subtype in acute myeloid leukemia clonogenic cells. J Interferon Cytokine Res 22: 335-341, 2002.

9 Wakao D, Murohashi I, Tominaga K, Yoshida K, Kishimoto K, Yagasaki F, Itoh K, Sakata T, Kawai N, Kayano H, Suzuki T, Matsuda A, Hirashima $\mathrm{K}$ and Bessho M: Serum thymidine kinase and soluble interleukin-2 receptor predict recurrence of malignant lymphoma. Ann Hematol 81: 140-146, 2002.

10 Elmore S: Apoptosis: a review of programmed cell death. Toxicol Pathol 35: 495-516, 2007. 
11 Yoshida K, Murohashi I and Hirashima K: p53-independent induction of $\mathrm{p} 21$ (WAF1/CIP1) during differentiation of HL-60 cells by tumor necrosis factor alpha. Int J Hematol 65: 41-48, 1996.

12 Cao Y, Nishihara R, Wu K, Wang M, Ogino S and Willett WC: The population impact of long-term use of aspirin and risk of cancer. JAMA Oncol 2: 762-769, 2016.

13 Kong Y, Cui H, Ramkumar C and Zhang H: Regulation of senescence in cancer and aging. J Aging Res 2011: 963172, 2011.

14 Ohtani N, Mann DJ and Hara E: Cellular senescence: its role in tumor suppression and aging. Cancer Sci 100: 792-797, 2009.

15 Galluzzi L, Joza N, Tasdemir E, Maiuri MC, Hengartner M, Abrams JM, Tavernarakis N, Penninger J, Madeo F and Kroemer G: No death without life: vital functions of apoptotic effectors. Cell Death Differ 15: 1113-1123, 2008.

16 Krysko DV, Vanden Berghe T, Parthoens E, D'Herde K and Vandenabeele P: Methods for distinguishing apoptosis from necrotic cells and measuring their clearance. Methods Enzymol 442: 307-341, 2008.

17 Nikoletopoulou V, Markaki M, Palikaras K and Tavernarakis N: Crosstalk between apoptosis, necrosis and autophagy. Biochim Biophys Acta 1833: 3448-3459, 2013.

18 Drullion C, Tre' goat C, Lagarde V, Tan S, Gioia R and Priault M: Apoptosis and autophagy have opposite roles on imatinibinduced K562 leukemia cell senescence. Cell Death Dis 3: e373, 2012.

$19 \mathrm{He} \mathrm{H,} \mathrm{Xia} \mathrm{HH,} \mathrm{Wang} \mathrm{JD,} \mathrm{Gu} \mathrm{Q,} \mathrm{Lin} \mathrm{MC} \mathrm{and} \mathrm{Zou} \mathrm{B:} \mathrm{Inhibition}$ of human telomerase reverse transcriptase by nonsteroidal antiinflammatory drugs in colon carcinoma. Cancer 106: 1243-1249, 2006.

20 Bruedigam C, Bagger FO, Heidel FH, Kuhn CP, Guignes S and Song A: Telomerase inhibition effectively targets mouse and human AML stem cells and delays relapse following chemotherapy. Cell Stem Cell 15: 775-790, 2014.
$21 \mathrm{Li} \mathrm{Y}$ and Tergaonkar V: Non canonical functions of telomerase: implications in telomerase-targeted cancer therapies. Cancer Res 74: 1639-1644, 2014.

22 Liu T, Liang X, Li B, Björkholm M, Jia J and Xu D: Telomerase reverse transcriptase inhibition stimulates cyclooxygenase 2 expression in cancer cells and synergizes with celecoxib to exert anti-cancer effects. Br J Cancer 108: 2272-2280, 2013.

23 Ali M, Devkota S, Roh JL, Lee J and Lee HW: Telomerase reverse transcriptase induces basal and amino acid starvationinduced autophagy through mTORC1. Biochem Biophys Res Commun 478: 1198-1204, 2016.

24 Goldenberg L, Davis O and Baker C: Indomethacin-induced oligohydramnios. Am J Obstet Gynecol 160: 1196-1197, 1989.

25 Maity G, De A, Das A, Banerjee S, Sarkar S and Banerjee SK: Aspirin blocks growth of breast tumor cells and tumor-initiating cells and induces reprogramming factors of mesenchymal to epithelial transition. Lab Invest 95: 702-717, 2015.

26 Zhang Y, Liu L, Fan P, Bauer N, Gladkich J, Ryschich E, Bazhin AV, Giese NA, Strobel O, Hackert T, Hinz U, Gross W, Fortunato $\mathrm{F}$ and Herr I: Aspirin counteracts cancer stem cell features, desmoplasia and gemcitabine resistance in pancreatic cancer. Oncotarget 6: 9999-10015, 2015.

27 Khuda-Bukhsh AR, Das S and Saha SK: Molecular approaches toward targeted cancer prevention with some food plants and their products: inflammatory and other signal pathways. Nutr Cancer 66: 194-205, 2014. 